\title{
Robot Assisted Cystectomy with Intracorporeal Urinary Diversion versus Open Cystectomy - A Cohort Study of Outcomes within 90 Days
}

\author{
Maria Vestly Nielsen ${ }^{1}$, MHS, Dorthe Rytter, Assoc, PhD ${ }^{1}$, Jørgen Bjerggaard Jensen ${ }^{2 *}$ \\ ${ }^{1}$ Dept. of Public Health, Aarhus University, Denmark \\ ${ }^{2}$ Professor, DMSc.Dept. of Urology, Aarhus University Hospital and Dept. of Clinical Medicine, Aarhus \\ University, Denmark
}

*Corresponding Author: Jørgen Bjerggaard Jensen, Professor, DMSc.Dept. of Urology, Aarhus University Hospital and Dept. of Clinical Medicine, Aarhus University, Denmark, E-mail: jb@skejby.net

\begin{abstract}
Purpose: To investigate postoperative complications, operating time and length of stay (LOS)for patients with localized bladder cancer, treated with robot assisted radical cystectomy $(R A R C)$ with intracorporeal urinary diversion (ICUD)compared to those treated with open radical cystectomy (ORC).
\end{abstract}

Design and methods: This register-based cohort included 500patients (ORC $=320$, RARC-ICUD $=180)$ who underwent radical cystectomy in the period between 05.21.2013 and 11.31.2017in a single tertiary cancer center. Complications were classified by the Clavien-Dindo system. Major complications (Claviengrades 35), operating time, LOS and blood transfusion rates were analyzed using multiple regression or Wilcoxon Rank Sum Test. The outcomes were then analyzed in a periodized sub-analysis.

Results: Significantly fewer patients had blood transfusions in the RARC-ICUD group than in the ORC group (OR 0.20 (95\%CI 0.13;0.30, p <0.001)). Mean operative time was 31 minutes longer for RARC-ICUD compared to ORC $(95 \%$ CI 18;45, p<0.001). There was no significant difference in other parameters comparing the two groups. However, the difference in operating time and OR for hospital admissions $>16$ days, surgical intervention caused by complications, ICU admission and major complications in general, tended to decrease over time.

Conclusion: RARC-ICUD had lower transfusion frequency than ORC. Mean operating time for RARC-ICUD is 31 minutes longer than ORC, whereas no significant difference was found in other parameters. Moreover, the study indicates that the surgeons experience is important when comparing outcomes from RARC-ICUD and $O R C$.

Keywords: PSA, TRUS biopsy, Prostate cancer

\section{INTRODUCTION}

In patients with localized invasive bladder cancer, radical cystectomy (RC) with urinary diversion is gold standard of treatment. $\mathrm{RC}$ is a complex procedure with high morbidity and mortality. Some reports estimate complication rate above over $60 \%$ in open radical cystectomy (ORC) [1]

Robot assisted radical cystectomy (RARC) is increasingly used in $\mathrm{RC}$, though the complications for RARC vs ORC are not yet fully disclosed. Publications comparing RARC with ORC are primarily made in small study populations and compare ORC with "hybrid RARC" where the urinary diversion is performed extra corporeally [2-13] . Complications related to RARC with total intra corporeal urinary diversion (ICUD) compared to ORC is very sparsely investigated in small study populations $[14,15]$.

The aim of this study therefore, was to compare peri- and postoperative outcomes related to RC performed by RARC- ICUD vs ORC.

\section{MATERIALS AND METHODS}

\subsection{Study Population}

From a prospective database, we identified 500 patients with localized bladder cancer undergoing RC: RARC $(\mathrm{n}=180)$ or ORC $(n=320)$ in a single tertiary cancer centre in 
Denmark. The database extracted data from the electronical medical journal from Central Denmark Region and from the Danish Person Register, which has complete records of vital status in the country [16]. None of the patients were lost to follow-up regarding vital status or admissions within the region.

All RARC procedures were performed with intracorporeal urinary diversion (ICUD) whereas ORC was performed as a minilaparotomy where the skin incision is significantly smaller than a conventional open surgery-incision [17]. The indication for $\mathrm{RC}$ was either muscle-invasive bladder cancer or treatment failure in non-muscle invasive bladder cancer.

All recorded complications within 90 days were classified according to the Clavien Dindo System [18]. Complications were classified as Major Complications if the patient had to undergo surgical intervention, was admitted to ICU or died because of complications equivalent to Clavien3-5 [19].

The database was approved by the Danish Data Protection Agency (jr.nr:1-16-02-37-13).

\subsection{Statistical Analysis}

Normally distributed continuous variables were described by their mean and standard deviation and analyzed using multivariablelinear regression. Since llength of stay (LOS) was not normally distributed, it was summarized using interquartile ranges (IQR) and the difference between RARC and ORC was tested using Wilcoxon Ranked Sum test.

Multivariable logistic regression analyses were used to analyze the association between the surgical approach and blood transfusion, hospitalization >16 days, secondary surgery, admission to ICU, death and all major complications. Hospitalization cut off at 16 days was chosen based on national statistics of hospital admissions after RC. Thus, it represents the 75-percentile of LOS after RC in Denmark [20].

In order to assess whether the association between operating technique and perioperative complications was dependent on surgeon experience, sub-analysis was performed including an interaction-term between calendar year (2013, 2014-2015, 2016-2017) and operating technique in the multivariable logistic regression models. 2013 was seen as an introduction period to ICUD.

All statistical analyses were performed using the software program Stata 15. All tests were set to a significance level of 0.05 .

\section{RESULTS}

The distribution of gender, mean age, BMI and type of urinary diversion in the two surgical approach groups are shown in table 1. The data base only contained BMI data on 340 of the 500 patients

Mean age was significantly lower in RARCpatients whereas BMI was significantly higher in this group. Ileal conduit was the main type of urinary diversion in both groups although the proportion of patients receiving a neo bladder, was significantly higher among RARC patients compared to ORC $(7.8 \%$ and $2.5 \%$ respectively, $\mathrm{p}=0.006)($ table 1$)$.

Table1. Patient characteristics and type of urinary diversion

\begin{tabular}{|l|c|c|c|}
\hline & RARC n=180 & ORC n=320 & p \\
\hline Sex, male (\%) & $135(75.0)$ & $230(71.9)$ & 0.45 \\
\hline Age, years. Mean (sd) & $67.9(9.1)$ & $71.6(9.7)$ & 0.001 \\
\hline BMI Mean (sd) & $28.3(5.7) *$ & $26.2(4.2) *$ & $0.001^{*}$ \\
\hline Type of Urinary diversion & \multicolumn{3}{|}{} \\
\hline Ileal conduit (\%) & $160(88.9)$ & $307(96.0)$ & \\
\hline Neobladder (\%) & $14(7.8)$ & $8(2.5)$ & \\
\hline Indiana Pouch (\%) & $3(1.7)$ & $3(0.9)$ & \\
\hline Unknown (\%) & $3(1.7)$ & $2(0.6)$ & \\
\hline
\end{tabular}

RARC = Robotic-Assisted Radical Cystectomy, ORC= Open Radical Cystectomy

\section{*BMI: $n=100$ for RARC and $n=240$ for ORC}

The operating time is significantly longer for RARC than for ORC (323 vs 282 minutes). This mean difference of 41 minutes was however reduced to 31 minutes after adjustment for gender, age and type of urinary diversion $(\mathrm{p}<0.001)($ Table2). 
Robot Assisted Cystectomy with Intracorporeal Urinary Diversion versus Open Cystectomy - A Cohort Study of Outcomes within 90 Days

Table2. Outcomes within 90 days when comparing RARC with ORC

\begin{tabular}{|c|c|c|c|c|c|c|c|}
\hline & $\begin{array}{c}\text { RARC } \\
(\%)\end{array}$ & $\begin{array}{c}\text { ORC } \\
(\%)\end{array}$ & $\begin{array}{r}\text { Crude OR } \\
(95 \% \mathrm{CI})\end{array}$ & $\begin{array}{c}\text { Adjusted } \\
\text { OR** } \\
(95 \% \mathrm{CI})\end{array}$ & $\begin{array}{c}\text { Crude mean } \\
\text { difference } \\
(95 \% \mathrm{CI})\end{array}$ & $\begin{array}{l}\text { Adjusted } \\
\text { mean } \\
\text { difference } \\
(95 \% \mathrm{CI})\end{array}$ & p* \\
\hline $\begin{array}{c}\text { Blood transfusion, } \\
\text { yes , } n=495\end{array}$ & $66(36.7)$ & $\begin{array}{c}241 \\
(75.3)\end{array}$ & $\begin{array}{c}0.19 \\
(0.13 ; 0.28) \\
\end{array}$ & $\begin{array}{c}0.20 \\
(0.13 ; 0.30)\end{array}$ & & & $<0.001$ \\
\hline $\begin{array}{c}\text { Operating time } \\
\text { minutes, mean }(\mathrm{sd}) \\
\mathrm{n}=492\end{array}$ & $\begin{array}{l}323 \\
(74.8)\end{array}$ & $\begin{array}{c}282 \\
(73.9)\end{array}$ & & & $\begin{array}{c}* * * \\
41(27 ; 54)\end{array}$ & $\begin{array}{c}* * * \\
31(18 ; 45)\end{array}$ & $<0.001$ \\
\hline $\begin{array}{c}\text { hospitalization }>16 \\
\text { days, yes, } n=495\end{array}$ & $43(23.9)$ & 85 (26.6) & $\begin{array}{c}0.87 \\
(0.57 ; 1.32) \\
\end{array}$ & $\begin{array}{c}0.82 \\
(0.53 ; 1.27) \\
\end{array}$ & & & 0.38 \\
\hline $\begin{array}{c}\text { Secondary surgery, } \\
\text { yes, } n=495\end{array}$ & $41(22.9)$ & $70(21.8)$ & $\begin{array}{c}1.05 \\
(0.68 ; 1.64)\end{array}$ & $\begin{array}{c}1.03 \\
(0.65 ; 1.62)\end{array}$ & & & 0.91 \\
\hline $\begin{array}{c}\text { Admission to ICU, } \\
\text { yes, } n=495\end{array}$ & $16(8.9)$ & $28(8.8)$ & $\begin{array}{c}1.02 \\
(0.53 ; 1.93)\end{array}$ & $\begin{array}{c}1.13 \\
(0.58 ; 2.21)\end{array}$ & & & 0.72 \\
\hline Dead, yes $n=489$ & $3(1.7)$ & $17(5.3)$ & $\begin{array}{c}0.30 \\
(0.09 ; 1.05) \\
\end{array}$ & $\begin{array}{c}0.39 \\
(0.11 ; 1.45) \\
\end{array}$ & & & 0.16 \\
\hline $\begin{array}{c}\text { complication grade } \\
3-5, \text { yes, } n=495\end{array}$ & $44(24,4)$ & $80(25)$ & $\begin{array}{c}0,97 \\
(0,64 ; 1,48)\end{array}$ & $\begin{array}{c}0,97 \\
(0,62 ; 1,51)\end{array}$ & & & 0,88 \\
\hline
\end{tabular}

$R A R C=$ Robotic-Assisted Radical Cystectomy, ORC= Open Radical Cystectomy, All estimates are indicated as $R A R C$ relative to $O R C$

* p value is calculated from the adjusted estimates

** All estimates are adjusted for sex, age and type of urinary diversion

*** linear regression: mean difference in minutes between RARC and ORC, both crude and adjusted for sex, age and urinary diversion.

The risk of blood transfusion was $80 \%$ lower in the RARC group compared to the ORC group (OR 0.20 (95\% CI 0.13; 0.30, p <0.001)).

Overall, there was no significant difference between the operating techniques on the complications within 90 days: hospitalization $>16$ days, secondary surgery, admission to ICU, or all complication grade 3-5. Although not significant, the risk of death was $61 \%$ lower for RARC compared to ORC.

As the database only contained BMI data on 340 of the 500 patients, no adjustment for BMI was

Table3. Adjusted OR/ time difference when comparing RARC with ORC regarding complications within 90 days, divided by period

\begin{tabular}{|l|c|c|c|c|}
\hline & \multicolumn{3}{|c|}{ Adjusted OR (95\% CI) } & \\
\hline & $\mathbf{2 0 1 3} \mathbf{~ n = ~ 5 0}$ & $\mathbf{2 0 1 4 - 2 0 1 5} \mathbf{~ n = 2 1 7}$ & $\mathbf{2 0 1 6 - 2 0 1 7} \mathbf{~ n = 2 3 3}$ & $\begin{array}{c}\text { p value for } \\
\text { interaction }\end{array}$ \\
\hline Blood transfusion, yes & $0.20(0.04 ; 0.89)$ & $0.17(0.09 ; 0.33)$ & $0.23(0.13 ; 0.41)$ & 0.79 \\
\hline $\begin{array}{l}\text { Difference in mean } \\
\text { operating time, minutes }\end{array}$ & $147(101 ; 192)^{* *}$ & $12(-9 ; 33) * *$ & $22(4 ; 40) * *$ & $\mathrm{P}<0.001$ \\
\hline $\begin{array}{l}\text { Hospitalization }>16 \\
\text { days, yes }\end{array}$ & $1.0(0.21 ; 4.61)$ & $0.81(0.39 ; 1.7)$ & $0.76(0.41 ; 1.38)$ & 0.94 \\
\hline Secondary surgery, yes & $0.86(0.15 ; 4.85)$ & $1.42(0.69 ; 2.93)$ & $0.78(0.41 ; 1.47)$ & 0.46 \\
\hline Admission to ICU, yes & $2.03(0.16 ; 25.40)$ & $1.14(0.38 ; 3.47)$ & $0.92(0.38 ; 2.25)$ & 0.83 \\
\hline Dead, yes & $* * *$ & $* * *$ & $* * *$ & $* * *$ \\
\hline $\begin{array}{l}\text { Complication grade 3- } \\
5, \text { yes }\end{array}$ & $0.68(0.12 ; 3.79)$ & $1,17(0.57 ; 2.38)$ & $0,84(0.46 ; 1.55)$ & 0.73 \\
\hline
\end{tabular}

$R A R C=$ Robotic-Assisted Radical Cystectomy, ORC= Open Radical Cystectomy, Estimates are indicated as $R A R C$ relative to $O R C$

* All estimates are adjusted for sex, age and type of urinary diversion

ARC Journal of Urology

Page |3 
** Linear regression: mean difference in minutes between RARC and ORC, adjusted for sex, age and urinary diversion.

*** Population too small for adjustment

The variables blood transfusion, hospitalization $>16$ days, secondary surgery, admission to ICU, death and all complication grade 3-5, revealed no statistically significant difference between the periods, although a tendency towards a decrease in OR for several outcomes was seen from the period 2014-15 to2016-2017.

\section{DISCUSSION}

As mentioned, earlier studies that compare RARC with ORC are mostly a comparison of RARC-ECUD and ORC and are performed with very small study populations. However, the articles from Chowet al.[15] and Atmacaet al.(14)present results comparing RARC-ICUD technique with ORC. Both studies find that RARC-ICUD leads to significantly lower blood loss and longer operating time, and finds no significant difference in Clavien 3-5 complications or LOS.

This is in accordance with the findings in the present study where we found that significantly fewer patients received blood transfusions in the RARC-ICUD group compared to the ORC group, and that RARC-ICUD on average takes 31 minutes longer than ORC to perform.

In May 2018, The InternationalRobotic Cystectomy Consortium (IRCC) presented a comparison of RARC-ICUD and hybrid RARC (ECUD) in 2125 RARC patients operated in 2013-2016(21).The Consortium found overall, shorter operating time (357 vs 400 minutes $\mathrm{p}$ $<0.001$ ), fewer blood transfusions (4\% vs $19 \%$, $\mathrm{p}<0.001)$ but also more major complications $(13 \%$ vs $10 \%, p=0.02)$ for ICUD compared to ECUD. The level of complications, however, decreases significantly over time in line with greater experience with the procedure [21].

ICUD thus appears to have advantages over ECUD. Therefore a greater contrast between RARC- ICUD and ORC was expected in the current study- compared to findings in previous studies comparing hybrid RARC with ORC [213].However, this lack of clear clinical benefitmight be a result of the technique used for ORC which is mini-laparotomy in our institution, whereas previous studies assumable used maximum incision-technique.The smaller incision results in fewer wound complications, decreased need for opioids and shorter LOS(17), leaving a smaller contrast between ORC and RARC-ICUD.
In line with IRCC, this study also finds that the complication rate of RARC-ICUD tended to deceas over time, indicating an effect of the surgeons' experience.

This study finds that the risk of secondary surgery and Clavien 3-5 complications are greater for RARC than ORC in 2014-2015 while ORC has higher risk of secondary surgery and grade 3-5 complications in 2013 and 2016-2017. One possible explanation for this may be due to the inclusion of more complicated patients, as well as more complicated urinary diversions in 2014, after becoming more experienced in ICUD.

The selection of patients to RARC-ICUD or ORC, respectively, is based on patient parameters such as BMI, heart/lung disease, neoadjuvant treatment and previous abdominal surgery. This study is limited by missing information on these parameters as it limits the degree of possible confounder control to age, gender and type of urinary diversion. The strengths are no loss to follow-up om vital parameters and hospital admissions as well as a larger study population than previous studies.

\section{CONCLUSION}

RARC-ICUD had lower transfusion frequency than ORC. Mean operating time for RARCICUD is 31 minutes longer than for ORC, but the difference in operating time minimizes as the surgeon obtain greater experience with RARC-ICUD. No significant difference was found in other parameters.

It is possible that the lack of significant differences between the outcomes of RARCICUD and ORC in this study is due to the ORC being performed with minimal incision technique.

Moreover, the study shows that the learning curve is important when comparing outcomes from RARC-ICUD and ORC.

\section{REFERENCES}

[1] Son SK, Lee NR, Kang SH et al.Safety and Effectiveness of Robot-Assisted Versus Open Radical Cystectomy for Bladder Cancer: A Systematic Review and Meta-Analysis. J Laparoendosc Adv Surg Tech A 2017 Nov; 27(11):1109-1120.

[2] Cusano A, Haddock P,Jr, Jackson M et al. A comparison of preliminary oncologic outcome and postoperative complications between patients undergoing either open or robotic 
radical cystectomy. Int Braz J Urol 2016 JulAug;42(4):663-670.

[3] Bak DJ, Lee YJ, Woo MJ et al. Complications and oncologic outcomes following robotassisted radical cystectomy: What is the real benefit? Investig Clin Urol 2016 Jul;57(4):260267.

[4] Gandaglia G, Karl A, Novara G et al. Perioperative and oncologic outcomes of robotassisted vs. open radical cystectomy in bladder cancer patients: A comparison of two highvolume referral centers. Eur J Surg Oncol 2016 Nov;42(11):1736-1743.

[5] Hu JC, Chughtai B, O'Malley $\mathrm{P}$ et al. Perioperative Outcomes, Health Care Costs, and Survival After Robotic-assisted Versus Open Radical Cystectomy: A National Comparative Effectiveness Study. Eur Urol 2016 Jul;70(1):195-202.

[6] Kader AK, Richards KA, Krane LS et al.Robotassisted laparoscopic vs open radical cystectomy: comparison of complications and perioperative oncological outcomes in 200 patients. BJU Int 2013 Aug;112(4):E290-4.

[7] Khan MS, Gan C, Ahmed Ket al. A Singlecentre Early Phase Randomised Controlled Three-arm Trial of Open, Robotic, and Laparoscopic Radical Cystectomy (CORAL). Eur Urol 2016 Apr;69(4):613-621.

[8] Messer JC, Punnen S, Fitzgerald J et al.Healthrelated quality of life from a prospective randomised clinical trial of robot-assisted laparoscopic vs open radical cystectomy. BJU Int 2014 Dec;114(6):896-902.

[9] Musch M, Janowski M, Steves A et al. Comparison of early postoperative morbidity after robot-assisted and open radical cystect omy: results of a prospective observational study. BJU Int 2014 Mar;113 (3): 458-467.

[10] Niegisch G, Albers P, Rabenalt R. Perioperative complications and oncological safety of robot-assisted (RARC) vs. open radical cystectomy (ORC). Urol Oncol 2014 Oct;32 (7):966-974.

[11] Smith ND, Castle EP, Gonzalgo ML et al. The RAZOR (randomized open vs robotic cystectomy) trial: study design and trial update. BJU Int 2015 Feb;115(2):198-205.

[12] Bochner BH, Dalbagni G, Sjoberg DD et al. Comparing Open Radical Cystectomy and Robot-assisted Laparoscopic Radical Cystectomy: A Randomized Clinical Trial. Eur Urol 2015 Jun;67(6):1042-1050.

[13] Winters BR, Bremjit PJ, Gore JL et al. Preliminary Comparative Effectiveness of Robotic Versus Open Radical Cystectomy in Elderly Patients. J Endourol 2016 Feb;30(2):212-217.

[14] Atmaca AF, Canda AE, Gok B et al.Open versus robotic radical cystectomy with intracorporeal Studer diversion. JSLS 2015 JanMar;19(1):e2014.00193.

[15] Chow K, Zargar H, Corcoran NM et al. Robotic-assisted radical cystectomy with intracorporeal urinary diversion versus open: early Australian experience. ANZ J Surg 2018 Jan 8.

[16] Pedersen CB. The Danish Civil Registration System. Scand J Public Health 2011 Jul;39(7 Suppl):22-25.

[17] Jensen JB, Pedersen KV, Olsen KO et al. Minilaparotomy approach to radical cystectomy. BJU Int 2011 Oct;108(7):1125-1130.

[18] Mitropoulos D, Artibani W, Biyani CS et al.Validation of the Clavien-Dindo Grading System in Urology by the European Association of Urology Guidelines Ad Hoc Panel. Eur Urol Focus 2017 Mar 7.

[19] Clavien PA, Barkun J, de Oliveira MLet al. The Clavien-Dindo classification of surgical complications: five-year experience. Ann Surg 2009 Aug;250(2):187-196.

[20] Dansk BlæreCancer Gruppe (DaBlaCa). Årsrapport 2016. 9. februar 2017; Available at: https://www.sundhed.dk/content/cms/86/15686 _dablacadata_-\%C3\%A5rsrapport_2016_ver17_rettet.pdf.

[21] Hussein AA, May PR, Jing Z et al. Outcomes of Intracorporeal Urinary Diversion after Robot-Assisted Radical Cystectomy: Results from the International Robotic Cystectomy Consortium. J Urol 2018 May;199(5):1302-13 11.

Citation: Maria Vestly Nielsen, Dorthe Rytter, Jørgen Bjerggaard Jensen. Robot Assisted Cystectomy with Intracorporeal Urinary Diversion versus Open Cystectomy - A Cohort Study of Outcomes within 90 Days. ARC Journal of Urology.2019; 4(1):1-5.doi:dx.doi.org/10.20431/2456-060X.0401001.

Copyright: () 2019 Authors. This is an open-access article distributed under the terms of the Creative Commons Attribution License, which permits unrestricted use, distribution, and reproduction in any medium, provided the original author and source are credited. 